\title{
Factors Influencing the Use of Mobile Learning in Learning at Jordanian Universities from the Point of View of Experts and Students
}

\author{
Dr. Tahani Ahmed Hamid Al-deeri \\ School of Um Atiya Alansariya Mixed Elementary, South Amman \\ Dr. Mansour Ahmad Alwraikat Prof \\ The University of Jordan, Amman
}

\begin{abstract}
This Study Aimed to Identify Factors Influencing the Use of Mobile Learning in Instructional in Jordanian Universities from the Point of View of Experts and Students. The Study Followed the Qualitative Curriculum as Required by the Nature of the Study, the Number of Study Members (19) Faculty Members and (25) Students of Bachelor's and Graduate Students from Public and Private Universities for the Academic Year (2019-2018), the Interview Questions were Built to Reveal Obstacles Faced by Jordanian Universities in the Use of Mobile learning in Instructional.

The Results of the Study Revealed that the Opening of a Wide Area of Interaction, Participation, Opinion, Feedback, and Faculty Factor in Terms of Directions, and Training Received the Highest Percentage of Factors Influencing the Use of Mobile Learning from the Point of View of Experts, as it Turns out that the Containment of Mobile Learning Devices For a Clear Learning System, the Educational Services Provided such as Content Delivery, Message Sharing, Ideas and Tasks have the Highest Percentage of Factors Influencing the Use of Mobile Learning from the Student's Point of View. The Study also Concluded with the Following Recommendation: to Introduce the Factors Influencing the Use of Mobile Learning in Instructional in Jordanian Universities and to Study them well, to Take into Account them When Using Mobile Learning in Universities. Key Words: Factors Influencing, Mobile Learning, Experts, Jordanian Universities.
\end{abstract}

DOI: $10.7176 / \mathrm{JEP} / 11-16-15$

Publication date: June 30th 2020

\section{Introduction}

Mobile Learning in Higher Education Institutions Faces Some of the Factors that Effect its Importance in Higher Education Institutions, Which Requires them to Consider the Factors Influencing the Use of Mobile Learning and to Work on Solutions to Take Advantage of Mobile Learning Applications in Instructional.

The Use of Mobile Learning Devices in the Educational Process is Justified by the Most Important of which is to Overcome Some of the Problems Experienced by Regular Education, Such as those Who Want to Complete their Education and Cannot Attend Regularly due to Barriers (Geography, Age, Etc.); Anywhere and any Time; Face-to-Face, Facilitates the Presentation Process and Develops Students' Abilities in Performing Activities and Accessing Various Scientific Resources (Ramzi, 2016).

Mobile Learning is Defined as "The Association of E-Learning Systems with Modern Mobile Device Technologies to Provide Knowledge and Information as one of the Methods of Applying on-Site Learning" (Yusuf, 2014, P.177).

Mobile Learning is Essential to Meet The Learning Needs Through Mobile Devices, and an Initiative to Gain Knowledge by Quickly Accessing Information, Interactive in the Learning and Response Process for Students to be Asked by Phone and Flexibility for A Large Number of Activities (Bukharaev And Altaher, 2017).

There are Many Services Provided by Mobile Learning Devices, Including: Short Messages Service (SMS) that Allows you to Communicate with Someone Else Anywhere; Social Apps that Allow Free Calls and Messages to Anyone; Bluetooth Service; Mobile-Memo (Mehdi, 2017).

Higher Education Institutions are Interested in Understanding and Interpreting Educational Materials by Taking Advantage of Mobile Learning Devices with the Ability to Design Models that Serve the Learning Process. Presented at this Conference Focuses on the Production of Educational Materials with Mobile Learning (El-Hussein And Cronje, 2010).

The Success Factors for Mobile Learning Projects are Determined by: Mobile Communication, Integration through the Integration of Mobile Learning Projects into the Curriculum and Student Experience, Institutional Support in the Design of Relevant Resources in Mobile Learning Forms; Mobile Learning to Support Teachers (Prasertsilp, 2013). 


\section{Statement of the Problem and Research Questions}

Wali's (2008) Study Indicated the Growing Interest in Mobile Learning, which Did not Achieve What the Concept was Aiming for Well, so the Relationship Between Context (The Attitude that Calls for Mobile Learning) and the Learning Practices Used in Higher Education Institutions Had to be Explored. The Study Showed that Mobile Learning Devices Enable Students to Engage in Learning Activities and Create Contexts Instead of the Old Devices Used in those Institutions, and We Can Consider Mobile Learning as an Approach to Promote Learning in Different Contexts. Higher Education Institutions are Trying to Benefit Mobile Learning to Improve and Develop The Educational Process for Students, Mobile Learning Providing A New Learning Environment that Allows Access to Students Outside The Walls of the Halls (Al-Subai'i and Al-Ghamdi, 2014).

While Studying at the University for the Two Stages (Bachelor's, Master's Degree), The Researcher Noted that the Use Of Mobile Learning in Instruction is Confronted by Some Factors Influencing the Use of Mobile Learning in Instruction. The Study Attempts to Answer the Following Question: What are the Factors Influencing The Use of Mobile Learning in Instructional in Jordanian Universities from the Point Of View of Experts (Faculty) And Students?

\section{Aimed Study}

The Current Study Aimed to Uncover the Factors Influencing the use of Mobile Learning in Instructional in Jordanian Universities from the Point of View Of Experts (Faculty) and Students, and Enrich Educational Literature in the Field of Mobile Learning.

\section{Significance of the Study}

Mobile Learning is A Necessity to Build Collaborative Knowledge through the Exchange of Knowledge and Experience, Enable students to Develop Experience Related to their Interests And Mobile Learning Helps Highlight Need Models Frameworks that Can Guide the Design and Evaluation of Mobile Learning Experiences (Hsu And Ching, 2015).

The Results of this Study Can Benefit Decision Makers in Jordanian Higher Education, Jordanian Public and Private Universities, to Identifying the Factors Influencing Use of Mobile Learning in Instructional in Jordanian Universities from the Point of View of Experts (Faculty) and Students, to Make Appropriate Decisions to Raise the Level of this Type of Education in Accordance with the Requirements of the Times. The Study May Benefit Workers from Jordanian Public and Private Universities From Learning About The Factors Influencing The Use Of Mobile Learning in Instructional in Jordanian Universities.

\section{Limitations of the Study}

The Results of the Current Study are Generalized in the Light of the Following:

1. Human Limited: This Study Was Limited to Faculty Members in Jordanian Public and Private Universities, Where the Number of Students (19) Members of the Study, and the Number of Students (25) Bachelor's Students from the Faculty of Information and Communication Technology, Graduate Studies (Specialization in Education Technology).

2. Spatial and Temporal Limits: The Current Study Was Limited to Jordanian Public and Private Universities from the 2018/2019 Academic Year.

3. The Study Tools Limited to Interviews Because of their Suitability for the Nature and Methodology of the Study.

\section{Operational Definitions}

Mobile Learning: Defined as the Use of Wireless Devices Such as Smartphones And Small Tablets, Which Can be Used in Teacher-Student Communications for Flexibility and Interaction (Bukharaev and Altaher, 2017). It is Defined Procedurally as: The Use of Mobile Learning Devices in the Instructional Process by University Students in Jordan.

Jordanian Universities: Defined Procedurally as Public and Private Universities in the Hashemite Kingdom of Jordan.

Experts: They are Experienced Faculty Members at Jordanian Universities Who Specialize in Using Mobile Learning in Instructional.

\section{Literature Review}

Instructional

Instructional is Defined as "A Human Activity Aimed at Providing Material and Psychological Conditions that Help Achieve Goals, A Position Characterized by the Interaction Between two Parties (Teacher and Student) Each With Roles to Achieve Certain Goals" (Al-Qaraa, 2013, P.14). We Define it as "A Purposeful Educational Process that Takes into Account the Development of all the Factors that Make up Education" (Khalil, 2011, P.2). 
Mobile Learning

Mobile Learning is Defined as Any Activity that Allows Students to be more Productive When Using or Interacting with Information A Digital Device that is Regularly Carried by the Individual and Has Reliable Communication, and Can be Used Anywhere and at Any Time by Wireless Access (Fakomogbon And Bolaji, 2017)

Students are Easily Viewed as Accessing Educational Materials with Wireless Networks and Mobile Devices (Akman And Kocoglu, 2017)

\section{Mobile Learning Characteristics}

File Sharing Between Students Themselves and Teacher is A Feature of Mobile Learning, and the Majority of Mobile Devices Have Reduced their Cost, and the Small Size of those Devices is Easy to Navigate, and Get Educational Information Faster Through the Services Provided by Mobile Learning Devices with Downloading Notes and E-Books (Bukharaev And Altaher, 2017).

Benefits of Mobile Learning

The Benefits of Mobile Learning Include Making Learning Environments more Attractive and Exciting, Activating Simultaneous and Asynchronous Communication Through Mobile Learning Techniques, Students Can Learn When Walking or Travelling, Achieving Some Degree of Skill Acquisition (Bas And Sarigoz, 2018).

Mobile Learning is Characterized by Practicality and Transportability Where it Allows to Take Notes, Write Text or Record A Voice Regardless of the Student's Location; The Availability of Educational Materials and the Retention of Knowledge, Mobile Learning Provides Quick Reminders and Additions to Materials (Gezgin; Adnan and Guvendir, 2018)

Mobile Learning Services

There are Many Services Provided by Mobile Learning Devices, Including: Short Messages Service (Sms) that Allows you to Communicate with Someone Else Anywhere; Social Apps That Allow Free Calls and Messages to Anyone; Bluetooth, Which Covers A Distance of 1 to 100 Metres, Mobile-Memo, A Tool for Collecting and Acquiring Information for Students (Mahdi, 2017).

One of the Services is the Presence of A Camera that Serves Many Educational Practices, Where Students Can Read Materials Electronically and Watch Lectures Using A Mobile Phone, The Camera Allows The Documentation of Visual Materials and the Collection of Scientific Data (Hilao and Wichadee, 2017).

Requirements For The Use Of Mobile Learning In The Educational Process

To Get the Right Use of Mobile Learning there are A Range of Basic Requirements Including: Convincing Students, Teachers and Management of the Importance of Using Mobile Learning Within Schools and Educational Centers; Converting Educational Materials and Curricula into Formats that are Appropriate and Mobile Learning with the Inclusion of Scientific Contents of Educational Materials in Formats Commensurate with the Network and Interactions with Students (Al-Armiti, 2015). Universities and Higher Education Institutions Need to Think about How Teachers Can Become MORE Skilled in Designing and Delivering Learning with Help of Mobile Learning Applications to Make Learning Better (Ali, 2018).

Educational Applications of Mobile Learning in Instructional

Mobile Learning is an Extension of Learning and Does not Replace Current (Systemic) Learning, Mobile Learning Applications Include The Creation of Wechat, Which Provides Oral, Audio, Visual Information And Contains A Virtual User Interface that Provides A Video to Arouse Interest (Dai And Liu And Cui, 2018).

Mobile Cloud Learning is A Student-Centric Mobile Learning Application that Meets Students' Needs and Takes into Account their Educational Characteristics. The Cloud Allows The Knowledge and Expertise of Students to be Shared Through Websites (Wang, Chen, And Khan, 2014).

Factors Influencing Use of Mobile Learning

The Success of Mobile Learning Projects is Determined by Several Factors: Integration, Namely, Integration of Mobile Learning Projects into the Student's Experiences and Daily Life; Institutional Support in Terms of Designing Mobile-Related Resources; Providing Technical Support; Caring About Student Needs; and Factors Influencing Use of Mobile Learning Community Culture (Mohamad and Al-Ameen, 2014).

Factors Influencing The Use of Mobile Learning Include Personal Factors Such as Age and Desire, Support by Teachers, Colleagues and Parents, The Advantages of the Network Used, the Type Of Devices, The Material Cost and the Instructional Methods of Teachers (Parajuli, 2016).

The Following Factors Influence the Use of Mobile Learning in Universities: Services Provided Through Mobile Devices, Easy Access to Learning Resources, Access to the University's Network, The Presence of 
Courses Organized by the University and Accessible Through Devices. Mobile and Appropriate Infrastructure (Lai and Mao, 2014).

Technological Factors Influence University Students' Use of Mobile Learning Technology Include: Interface, Collaboration Tools, Internet Access and Protocols for Document Transfer 2016 (Ogunlade, Olafare And Sakaba),

Students' Characteristics of Personal Creativity, The Expected Performance of Students and the Learning Style are Factors Influencing the Use of Mobile Learning (Karimi, 2016).

The Context Factor is Influential in the Use of Mobile Learning and Includes Useful Applications, Activities and the Student Trust Factor Towards Mobile Learning in Terms of Protection and Privacy (Hamidi and Ghavoshi, 2017).

\section{Previous Studies}

Lai and Mao(2014) Conducted A Study Aimed at Answering Factors Influencing Mobile Learning for Undergraduate Students; The Telephone Network Infrastructure in Universities is Very Good, The SelfEfficiency of Students is Very High, and More than $96 \%$ of Phone Participants Use The Internet to Connect the Internet, Most of Whom Believe they Have the Ability to Use Phone and Mobile Learning Devices; The Colleagues Were Unsatisfactory, 25.4\% Agreed to the Item (The Teacher Encouraged Me to Use Mobile Learning) and 96\% Agreed to the Item (The Cost of Mobile Devices is Cheap for Me).

Nawi, Hamzah, Ren and Tamuri (2015) Conducted A Study to Determine the Readiness of Teachers to Use Mobile Phones for Instructional Purposes; The Study Sample Included (31) Teachers; to Achieve the Objective of the Study, Seven Teachers Were Interviewed for Supporting Data; A 50-Year-Old Employee's Age Factor Was also Found to be the Same. The Results also Indicated that the Use of Mobile Phones among Teachers Was Appropriate and Facilitated Educational Activities; The Results Indicated the Impact and Priority of Technical Aspects on the Usability Aspects of Practical Application.

Ogunlade, Olafare and Sakaba (2016) Conducted A study Aimed at Identifying Technological and Individual Factors Influencing the Use of Mobile Learning Technology at the University of Ilorin in Nigeria; The Sample Included (100) Students; Individual and Technological Factors Were also Examined by Testing their Relationship; The Results Indicated Technological and Individual Factors that Positively Influenced Benefit of University Students' Learning, The Results also Indicated A Positive Relationship Between Technological and Individual Factors Influencing Mobile Learning Technology.

Karimi's (2016) Conducted A study Aimed to Identify Individual Characteristics That Motivate Students to Use Mobile Learning; The Sample Included (130) Students from A Uk University; to Achieve the Aimed of the Study, A Questionnaire Was Used that Included 7 Areas on the Leckert Seven Scale and A Learning Pattern Tool Was Designed Describing Kolb 12 Learning; The Results Indicated that Individual Learning Style Influences the Use Of Mobile Learning in Learning Situations, While Expected Performance and the Ability to Create Personally Do not Affect Learning Contexts; Also Noted that the Adoption of Mobile Learning is Influenced by A Number of Characteristics the Environment and Individuals.

Hamdi And Javoshi(2017) Conducted A Study Aimed at Assessing the Key Factors in the Adoption and Application of the Information System; The Sample Included (300) Students from the Faculty of Technology from Tusi K. N. Toosi University in Iran; to Achieve Aimed of the Study, A 28-Question Information Collection Questionnaire Was Used on the Five-Point Leckert Scale, and the Results Indicated that Mobile Learning Could be One of the Most Promising Learning Techniques for Development in Educational Environments; The Results also Noted The Positive and Significant Impact of the Context of Applications on Ease of Use and Benefit and Noted that Personal Features Have A Significant Positive Impact on A Culture of Use that Has A Positive Impact on Behavioural Intent.

Almaiah and Alismaiel (2019) Conducted A Study Aimed to Integrate the TAM Model with the Delone and Mclean Models to Examine Quality Factors and Individual Beliefs Leading to Enhanced Mobile Learning; The Study Sample Included (400) Students Distributed at Five Universities in Jordan; to Achieve The Aimed of the Study, A Five-Year-Old Leckert-Based Questionnaire Was Used; The Results Indicated that Quality Factors (System Quality, Information Quality, Service Quality) Have an Impact on Students' Determination to Use Mobile Learning; The Results also Indicated the Perceived Benefit, Comfort and the Willingness to Use an Impact on the Actual Use of Mobile Learning.

\section{Summary}

After Reviewing Previous Studies and Research, it is Noted that there are Agreements with the Current Study in Many Subjects, Dealing With Studies (Lai And Mao, 2014), (Nawi, Hamzah, Ren And Tamuri, 2015), (Ogunlade, Olafare And Sakaba, 2016), (Karimi, 2016), (Hamidi And Ghafushi,2017), (Almaiah And Alismaiel,2019). Factors Influencing The Use of Mobile Learning in Instructional, Were Summarized in Technical, Technological and Physical Factors, Consisting of Infrastructure, The Cost of Mobile Devices, User 
Age, Learning Style and Perceived Benefit.

\section{Methodology}

This Study Used A Qualitative Approach in Which to Provide Comprehensive Explanations of the Subject of Research and Adopt The Exact Details and Extensive Explanations of the Phenomenon Therefore, the Overall Perspective of the Research, The Results of Which are Illustrative, Will Therefore be Conducted with Faculty and Students at Jordanian Universities, to Obtain Qualitative Data and then Analyze it with Qualitative Data Analysis Methods and Obtain Results.

There are Types of Qualitative Research and Phenotype are the Appropriate Type of Study, Where Phenotype is A Kind Of Qualitative Research Derived from Views

Philosophical People about their Knowledge, Attitudes and Experiences, as this Genre Aims to Explore Experiences in Specific Context and Methods of Aggregation (Data Collection) are Conducted Through InDepth Interviews (Taylor, 2014).

\section{Study Personnel for Qualitative Data}

Interviews Conducted with Faculty Members the 19 Faculty Members and 25 Students are Bachelor's Students From the College of Information Technology and Communications Technology (IT) and Graduate Studies (Specialization of Instructional Technology), from Public and Private Universities who wish to Answer The Interview Questions.

\section{Study Instrument: Interview}

After Reviewing the Relevant Literature and Reviewing the Previous Studies and Guiding them, and Based on the Nature of the Data to be Collected and According to the Methodology Used in the Study, and to Achieve the Objectives of the Current Study, The Researcher Based the Interview Questions for Faculty Members and Students to Answer the Question What are the Factors Influencing The Use of Mobile Learning in Instructional in Jordanian Universities from the Point Of View of Experts (Faculty) And Students? in order to Generate Knowledge that Provides the Researcher with the Obstacles Facing Jordanian Universities in the Use of Mobile Learning in Instructional, The Interview is One of the Tools Collecting Qualitative Data in Many Qualitative Research, for Several Considerations, Including: The Possibility of Presenting Additional Questions to Get More Information, The Possibility of Individual or Group Interviews, Data is Collected in an orderly Manner, Gestures and Forms of Language are Monitored( Kielmann, Cataldo And Seeley,2012).

\section{Validity}

The Validity of the Interview Questions was Verified by Presenting the Interview Questions in their Initial form to A Group of 17 Arbitrators with Specialties in Curriculum, Instructional, Instructional Technology, Measurement, Evaluation and Computer Science, in order to Ascertain the Diversity of the Interview Questions and the Degree of Clarity Questions and their Brevity, The Integrity of Language Language, The Objectives are Specific and Clear, The Questions are Raised to the Recipient's Attention, and any Amendments or Suggestions that the Arbitrators Deem Appropriate.

After Reviewing the Views and Observations of the Arbitrators, The Interview Questions were Reviewed and Amended Based on the Proposals of the Arbitrators and any Amendments they Found Appropriate, and the Amendments were the Reformulation of some Questions, The Deletion of Some Questions, and in the Light of the Amendments the Interview Questions Became in its Final Form. Distributed as follows: Faculty Interview Questions to Reveal Factors Influencing Use of Mobile Learning in Instructional Consisting of 6 Questions; Student Interview Questions to Reveal Factors Influencing the Use of Mobile Learning in Instructional Consisting Of 7 Questions.

Taking into Account That Honesty is A Specific Characteristic of Qualitative Research, The Researcher Derives the Facts by Collecting Data Directly.

\section{Reliability}

In Order to Verify the Stability of the Study Tool, the Researcher Calculated the Stability of the Interview Questions by Following the Stability of the Analysts, where One of the Colleagues who had the Ability to Perform the Analysis was Called after Training on the Analysis by the Researcher, to Calculate the Number of Agreement and the Number of Agreement of Difference According to the Equation Cooper Calculates the Analyst Agreement Coefficient on the Interview Questions Using the Following Equation:

Agreement coefficient $=\quad$ Number of Times the Agreement $\quad * 100 \%$

Number of times agreement + number of times not a deal


Accordingly, the Resulted in a Set of Data Described in the Following Table:

\begin{tabular}{|c|l|l|c|}
\hline Agreement & difference & Total & Percentage Agreement \\
\hline 31 & 2 & 33 & $93,9 \%$ \\
\hline
\end{tabular}

It is Obviously from the Previous Table (1) that the Average Coefficient of the Interview Analysis Agreement was (93.9), a High Percentage from which to be Assured of the Stability of the Interview Questions.

\section{Results of the Study}

The Findings Concerning the Answer to the Main Question State: " What are the Factors Influencing the Use of Mobile Learning in Instructional in Jordanian Universities from the Point of View of Experts (Faculty) and Students?

To Answer this Question, Section 1, Relates to the Faculty, Where I Conducted Personal Interviews with (19) Faculty Members of the Faculty of Information Technology and Communications and Specialists In Instructional Technology. The Specifications of the Faculty Interviewed Varied in Terms of Teaching Experience, Gender, Number of Computer Courses Received by the Faculty Member, Materials He Studied Through Mobile Learning, The Date and Time of the Interview.

The Qualitative Data Extracted from the Responses Were Analysed. the Results of the Faculty Interviews Indicated Factors Influencing Use of Mobile Learning in Instructional at Jordanian Universities and are Described in Table (2) and Arranged According to the Frequency of their Inclusion in Faculty Interviews. Here is A View of these Results:

Table (2) Descending Order of the Proportion of Factors Influencing the Use of Mobile Learning in Instructional in Jordanian Universities from the Point of View of Experts (Faculty).

\begin{tabular}{|c|l|c|c|}
\hline Number & \multicolumn{1}{|c|}{ The Factor Influencing the Use of Mobile Learning } & Frequency & Percentage \\
\hline 1. & $\begin{array}{l}\text { Open Up A Wide Range of Interaction, Participation, Opinion and } \\
\text { Feedback. }\end{array}$ & $100 \%$ \\
\hline 2. & Faculty Members in Terms of Directions, Training. & 19 & $100 \%$ \\
\hline 3. & $\begin{array}{l}\text { Students in Terms of Preparation, Encouragement, Acceptance of } \\
\text { Mobile Learning, Benefits, Needs and Taking into Account the } \\
\text { Individual Differences Between them. }\end{array}$ & $58 \%$ \\
\hline 4. & $\begin{array}{l}\text { The Role of the Ministry of Higher Education, Universities in its } \\
\text { Adoption and Dissemination. }\end{array}$ & 11 & $58 \%$ \\
\hline 5. & Infrastructure of Equipment and Tools. & 10 & $53 \%$ \\
\hline 6. & $\begin{array}{l}\text { Lack of A Special System and Standards that Support Mobile } \\
\text { Learning. }\end{array}$ & $53 \%$ \\
\hline 7. & Having A Technological Plan for Mobile Learning. & 9 & $53 \%$ \\
\hline 8. & Hardware in Terms of Specifications. & 7 & $47 \%$ \\
\hline 9. & $\begin{array}{l}\text { Applications, Programs, Simultaneous and Asynchronous } \\
\text { Communication. }\end{array}$ & 6 & $37 \%$ \\
\hline 10. & Ability to Change and Communicate. & 5 & $32 \%$ \\
\hline 11. & Connectivity and Slow Internet Availability. & 5 & $26 \%$ \\
\hline 12. & The System of Incentives and Rewards in Universities. & 4 & $26 \%$ \\
\hline 13. & Material and Digital Content. & & $21 \%$ \\
\hline
\end{tabular}

Note from Table (2) that the Ratio $(100 \%)$ of the Faculty Members Interviewed, the Two Factors that Influence the Use of Mobile Learning in Instructional are (Opening Up A Wide Range of Interaction, Participation, Opinion, Feedback) and (The Teaching Staff in Terms of Directions and Training).

With Regard to the First Paragraph, A Faculty Member (23 Years Of Experience, 25 Computer Courses) Indicated "If the Mobile Learning Method is Adopted in University Instructional, It will Certainly Open Up A Wide Range of Students to Interact and Participate in the Learning and Education Process, Regardless of Whether or not they are Simultaneous. This Enriches the Learning and Education Process Positively."

A Faculty Member (10 Years Experience, Many Courses) Added "Opens A Lot of Room for All Categories of Students, Especially those Who are less Involved in Traditional Learning Environments Who are Ashamed or Prevented From Doing so Because of Time or Place Limits."

Said A Faculty Member (9 Years Experience, 6 Courses) "Giving Feedback, Reading Lessons, Sites for Each Doctor, and Enriching the Process as A Whole".

With Regard to the Second Paragraph, A Faculty Member (23 Years of Experience, 25 Computer Courses) "The Role of Motivation among Faculty Members Varies by their Knowledge of How to Use Mobile Learning and their Attitudes Towards it."

"Teachers are Trained in Online Courses that are Easy to Trade in Mobile Learning," Added A Faculty 
Member (30 Years of Experience, 2 Courses).

Followed by (58\%) for the Student Workers in Terms of Preparation, Encouragement, Acceptance of Mobile Learning, the Extent of Benefits Needs and Taking into Account the Individual Differences Between them and the Role of the Ministry of Higher Education and Universities in Adopting and Disseminating it.

A Faculty Member (30 Years Experience, 2 Courses) "Referred to the Student Factor in Terms of Preparation, Encouragement, Acceptance of Mobile Learning, The Extent of Benefits Needs and Taking into Account the Individual Differences Between them and Encouraging Students to Use Mobile Phones in Education."

"In Light of the Great Advances Technology, We Must Plan to Provide Basic Requirements for Mobile Learning from Infrastructure, Convince Students, Parents to Learn Mobile and Financial Support," Said A Faculty Member (5 Years Experience, 12 Courses).

"Mobile Learning in General is Intended to Give Learner Freedom to Learn in Terms of Access to the Educational Material and Interaction with the Teacher in A Different Way from the Usual," Said A Faculty Member (20 Years Of Experience, 5 Courses).

As for the Fourth Factor, The Role of the Ministry of Higher Education and Universities in Adopting and Generalizing, A Faculty Member (23 Years Experience, 25 Computer Courses) Pointed Out that "Of Course this Needs to be Developed or Modified in the Instructions for the Granting of Degrees and Criteria for Adopting this Method (Mobile Learning) by the Ministry of Education. Higher and the Directorate Accreditation of Higher Education Institutions in Jordan."

"There Must be A Key Role for Universities to Adopt and Create Information and Adopt this Technology in Learning and Education," Said A Faculty Member (23 Years of Experience, Many Courses).

Added A Faculty Member (5 Years Of Experience, Not Taking Courses) "Responsible for the Ministry of Higher Education for the Use of Mobile Phones in Learning."

Previous Quotes Show that Students Themselves are A Factor Influencing The Use of Mobile Learning in Terms of their Acceptance of Mobile Learning, The Extent to Which Benefits from it, Universities and the Ministry of Higher Education Have also Played A Role in Adopting and Disseminating Mobile Learning.

53\% Followed by Factors (Infrastructure of Equipment and Tools), Lack of A Special System and Standards that Support Mobile Learning and (Having A Technological Plan for Mobile Learning).

With Regard to the Fifth Factor, The Infrastructure of Equipment and Tools Has Been Provided by A Faculty Member (23 Years of Experience, Many Courses) "In Adopting this Technology and Creating the Appropriate Infrastructure for it, then Implementing it and Adopting Certificates Issued by Institutions that Grant Degrees Using Mobile Learning."

"You Must Plan to Provide The Basic Requirements for Mobile Learning from Infrastructure," Added A Faculty Member (5 Years Experience, 12 Courses).

With Regard to the Sixth Factor, The Lack of A Special System and Standards Supporting Mobile Learning is

Cited by A Faculty Member (23 Years of Experience, 25 Computer Courses) "Providing Standards for the Adoption of Mobile Learning Style by the Ministry of Higher Education and the Accreditation Authority of Higher Education Institutions in Jordan."

"New Legislation Allows for Mobile Learning," Said A Faculty Member (47 Years of Experience, 10 Courses).

As for Factor Seventh, Having A Technological Plan for Mobile Learning, A Faculty Member (15 Years Of Experience, 30 Courses) Pointed Out that "Sure, A Long-Term Plan that Mobile Learning After 5 Years is What Would be Like, The Origin Being A Plan for the Basics, Not the Tools."

"The More Programmed and Planned the Work, The More Successful it is, But If it is Based on Randomness and Mood, The Results are Low and Unrewarding," Added A Faculty Member (30 Years of Experience, 2 Courses).

"There Has To be A Plan For this, But that Plan Must be Flexible to Take into Account the Continued Progress and Development of Educational Technology," Said A Faculty Member (23 Years of Experience, Many Courses).

Previous Responses Show that Factors Related to Factors (Infrastructure of Equipment And Tools; Lack of A Special System, Standards that Support Mobile Learning and the Existence of A Technological Mobile Learning Plan) Affect the Use of Mobile Learning in Universities.

Followed by $47 \%$ Hardware in Terms Of Specifications Where A Faculty Member (23 Years Experience, Lots of Courses) "The Presence of Appropriate Devices With Appropriate Specifications (Size, Speed, Memory, Cost).

"Providing Material and Technical Support in the Field of Mobile Learning," Added A Faculty Member (30 Years of Experience, 2 Courses).

The Answers of the Teaching Staff Refer to the Equipment Factor and Hardware Specifications, Which Serve as Mobile Learning Tools. 
Followed by (37\%) Applications, Programs, Simultaneous and Asynchronous Communication, A Faculty Member (47 Years Experience, 10 Courses) " Creating Requirements that Help Perform Mobile Learning is to Provide Opportunities for Students, Teachers For Mobile Learning Procedures, Provide Programs, Applications (Video, Video Conversation) Simultaneous and Asynchronous Communication Helps These Incentives to Support it."

"Programs that Fit the Mobile Phone in Ways that are Easy for Students to Eat, Study and Interact with," Added A Faculty Member (30 Years of Experience, 2 Courses).

"Opening Up A Space to Deal With Different Programs, Reach Out to Knowledge by Phone, and A Program that Delivers Information From Anywhere," Said A Faculty Member (9 Years of Experience, 6 Courses).

Previous Answers Show that Factor IX Applications and Programs Have A Role to Play in Supporting Mobile Learning.

Followed by $32 \%$ Of The Ability to Change and Communicate, A Faculty Member ( 5 Years of Experience, 25 Courses) Mentioned "Motivation, Willingness to Keep Up and Changeability among Faculty Members."

"A Few Accept Change and the Number is Limited and Depends on the Subject," Added A Faculty Member (9 Years Experience, 6 Courses) "A Few Accept Change, the Number is Limited and Depends on the Subject.""

It is Clear that the Tenth Factor is About Caring about Changeability, Keeping Pace so that Universities and Faculty Can Use Mobile Learning.

Followed by $26 \%$ Of Employees with Networkavailability, Slow Internet Connectivity, The Incentive and Reward System at Universities.

With Regard to the Availability of Networks and the Slowness of the Internet, A Faculty Member (25 Years of Experience, Lack Of Courses) Stated that "Making Agreements with the Telecommunications Companies Because the Lack of Offers is Expensive for the Student (Billing Fees)".

"Among them are Passive, Cheating, Quoting, Slow Internet," Added A Faculty Member (10 Years Experience, 10 Courses).

As for the Factor Incentive and Reward System in Universities, A Faculty Member (5 Years Experience, 25 Courses) Noted that "Sometimes if the University's Directions are to Activate A Specific System, The Incentive and Reward System Can be Activated to Increase the Response Rate."

"Incentives Have A Role to Play in Getting More Staff to Accept Mobile Learning," Added A Faculty Member (10 Years of Experience, Many Courses).

Previous Answers Show that Network Workers, The Incentive and Reward System at Universities Play A Role in the Use of Mobile Learning at Universities.

Followed by the Lowest $21 \%$ of the Material and Digital Content, Where A Faculty Member (5 Years Experience, 25 Courses) Mentioned "Experience, Skill, and Ability to Build Appropriate Electronic Content."'"

"Introducing Materials in A Computerized Way that allows Mobile Communication," Said A Faculty Member (4 Years of Experience, 2 Courses).

Previous Answers Refer to Interest in Material and Digital Content When Using Mobile Learning as A Factor in its Use.

The Researcher Believes that the Factors Influencing Use of Mobile Learning in Instructional in Jordanian Universities in General are due to Human Resources Factors that Include (Faculty, Students, Decision Makers in the Hierarchy of Educational Institutions); Factors Related to Software and Physical Components. for Mobile Learning (Availability of Devices And Appropriate Specifications such as (Size, Speed, Memory); Who Use Mobile Phones in Instructional, Provide Adequate Infrastructure and Provide Networks that Support Mobile Learning).

In Order for Universities to Adopt These Factors, Faculty, Students and Society Need to be Made Aware of the Importance of Mobile Learning, Which is Changing The Ability of Faculty Members to Move Forward with Mobile Learning.

As for the Reality of Jordanian Universities on the Use of Mobile Learning, There is No Official Use it, As Pointed Out by A Faculty Member (23 Years of Experience, 25 Computer Courses) "At Present there is No Use of Mobile Learning in Jordanian Universities Officially.""

But there is A Development in the Use of Mobile Learning in Some Jordanian Universities and this is What A Faculty Member (47 Years Experience, 10 Courses) "Many Arab Universities in this Field Have Exceeded, The Uses of Mobile Learning Began With Simple Steps And In A State Of Development And Perhaps The Most Prominent of Which are the Classifications you Find in the Arab Open University and Some Universities that Benefit From these Modern Patterns of Education."

With Regard to A Technological Plan for Mobile Learning, there is No Formal and Actual Plan to be Adopted in Jordanian Universities, Where A Faculty Member (25 Years of Experience, No Courses) "There is no Plan at the Moment, but Every University Works Alone, Jordan Alone and Yarmouk Alone. But Egypt has Worked for the Association of Education Technology."

It Turns Out that Jordanian Universities Themselves do not Offer Incentives to those who Follow or Use 
Mobile Learning, A Faculty Member (30 Years of Experience, 40 Courses) Said, "I Do not Know of Any Incentives for those Who Follow Mobile Learning, The Largest Beneficiary of Students, Faculty and Educational Institutions."

As it Turns Out that Some Jordanian Universities Do not Require Faculty Members to Activate Mobile Learning, A Faculty Member (25 Years of Experience, No Courses) Stated that "Yarmouk Prohibits the Use of Mobile Learning for Any Purpose, So there is no such Awareness Because the Student Does not Employ him in Education.

The Second Section Relates to the Student's Point of View, Where I Conducted Personal Interviews with (25) Graduate Students Specializing in Education Technolog and Bachelor's Students from the Faculty of Information Technology and Communications (IT). The Specifications of the Students Interviewed Varied in Terms of Educational Level, Gender, College Type, School Year, Date and Time of the Interview.

The Qualitative Data Extracted from the Responses Were Analysed. the Results of the Student Interviews Indicated Factors Influencing the Use of Mobile Learning in Instructional in Jordanian Universities, and are Described in Table (3) and Arranged According to the Frequency of their Presence in Student Interviews. Here is A View of these Results:

Table (3) Descending Order of the Proportion of Factors Influencing the Use of Mobile Learning in Instructional in Jordanian Universities from the Point of View of Students.

\begin{tabular}{|c|l|c|c|}
\hline Number & \multicolumn{1}{|c|}{ The Factor Influencing the Use of Mobile Learning } & Frequency & Percentage \\
\hline 1. & The Mobile Learning Devices have A Clear Learning System. & 25 & $100 \%$ \\
\hline 2. & $\begin{array}{l}\text { Educational Services such as Content Delivery, Message Sharing, } \\
\text { Ideas, and Tasks. }\end{array}$ & 25 & $100 \%$ \\
\hline 3. & $\begin{array}{l}\text { Faculty Members and their Role in the Design of the Material, } \\
\text { Encouragement and Awareness }\end{array}$ & 25 & $100 \%$ \\
\hline 4. & $\begin{array}{l}\text { Provide an Environment for Interaction, Participation and } \\
\text { Communication Through Dialogue and Discussion Groups }\end{array}$ & 25 & $100 \%$ \\
\hline 5. & Time, Effort, Place and Cost & 25 & $100 \%$ \\
\hline 6. & Devices and their Use. & 9 & $60 \%$ \\
\hline 7. & Educational Material and Content. & 9 & $36 \%$ \\
\hline 8. & Sources And References that Provide Additional Information. & $36 \%$ \\
\hline 9. & $\begin{array}{l}\text { Mobile Learning Management Services such as Follow-Up Lectures } \\
\text { and File Sending. }\end{array}$ & 9 & $36 \%$ \\
\hline 10. & Characteristics of Students. & 6 & $36 \%$ \\
\hline 11. & Scientific Research. & 6 & $24 \%$ \\
\hline 12. & Flexibility. & $94 \%$ \\
\hline
\end{tabular}

Note from Table (3) that the Ratio (100\%) of the Students Interviewed, The Factors Influencing The Use of Mobile Learning in Instructional Contain Mobile Learning Devices for A Clear Learning System; Educational Services such as Content Delivery, Message Sharing, Ideas and Tasks; Faculty Members and their Role in Material Design and Encouragement. The Government's Efforts to Address the Challenges of Past Have Been Very Difficult.

"The Clear Learning System Positively Affects the Use of Mobile Learning, Because it will Help Communicate the Learning Message more Effectively and Increase Teachers' Interaction with Each Other and with Content," a (postgraduate) student Said.

Added (Bachelor) Student "The Easier it is to Understand it and Use it Efficiently, Quickly and Therefore Better Results."

"There is A Clear and Academic Learning System that is Scientifically Based on Effective Teaching Design Models," Said A (postgraduate) Student.

With Regard to the Educational Services Provided, such as Content Delivery, Message Sharing, Ideas and Tasks, A (Bachelor) Student Noted, "Students are Allowed to Follow their Lessons and Exchange Messages between Learners Easily."

"There are many Educational Services, The most Important of Which are SMS Services, Whether Text or Multimedia and Use by Teachers to Follow Academic Courses for Students and Provide Feedback To Them; and to Provide Learners With The Required Educational Tasks," Said A (postgraduate) Student.

"Simply Because it Makes Easier for the Student to Access Information and has also Provided him with A Lot of Various Applications and Tools to Make it Easier for him to Understand A Lot of Materials for the Application with High Efficiency," Added A (Bachelor) Student.

With Regard to the Faculty Factor and their Role in the Design of the Material, Encouragement and 
Awareness, A (postgraduate) Student Mentioned "The Role of the Teacher is A Principal and Active Teacher, The Active Teacher is the One Who Generates Motivation among Students for Mobile Learning Through Direct Interaction with Students Online."

"Faculty Members Have an Important and Active Role in Encouraging Students to Use Mobile Learning through Many Ways, Including Being Activated within Teaching Meetings, or Being Done to do the Required Duties and Projects for the Subject," Said A (postgraduate) Student..

"The Role of Teaching is to Motivate Students, Let and Teach them (Educate Them) The Right Ways to Use Technology" Added A (Bachelor) Student.

With Regard to the Factor of Providing an Environment for Interaction, Participation, Communication Through Dialogue and Discussion Groups, A (postgraduate) Student Said "Has A Great Role to Play Through the Interaction and Interaction between Students both in Groups Over the Phone or in Learning Platforms and in Electronic Courses Where the Interaction between Students and Brainstorming are Mandatory to Evaluate the Learning Process."

"Use of Mobile Learning is One of the Main Tools in the Exchange of Ideas by Establishing the Authenticity of the Information and Showing its Source," Added A (postgraduate) Student.

"The Motivation is What's there and There's Communication with the Student for Discussion," A (Bachelor) Student Said.

With Regard to the Time, Effort, Place and Cost Factor, A (Postgraduate) Student Stated that "Learning is Provided at any Time and Place, There are no Geographical or Temporal Barriers to Learning."

"Not Being Able to Buy Devices Easily," Added A (Bachelor's) Student.

"Opening the Way for the Learner to Choose the Right Time and Time to Learn, Solve the Duties Required of him," Said A (Postgraduate) Student.

It is Clear from the Students' Responses that the Factors Mentioned above are Important and A Role in the Use of Mobile Learning in Instructional and this Indicates the Need to Adopt them as they Have Received $100 \%$. $60 \%$ Followed by the Hardware Factor and its Use, Where A (Bachelor) Student Mentioned "Not Knowing the Use of Mobile Devices".

"Storage Capacity, Screen Size, Battery Charge Access, Cost, Device Size," Added A (Bachelor) Student.

Previous Answers Show that the Device's Specifications (Size, Speed, Memory, And Knowledge of its Use) Affect Students' Use of Mobile Learning In Instructional.

Followed by $36 \%$ for the Following Factors: Educational Material and Content; Sources and References that Provide Additional Information; Administrative Services for Mobile Learning such as Follow-Up Lectures and File-Sending; and Student Characteristics.

With Regard to the Educational Material Factor and Content, (Postgraduate) Student Said "It May Contain Many Educational Books, Audio Clips and Instruction Videos.""

"The Scientific Content and the Design of the Teaching Instructional Which this Content Was Presented," Added A (Postgraduate) Student.

"The Educational Material Itself, The Design Method of the Educational Material," Said A (Postgraduate) Student.

With Regard to the Source and Reference Factor, A (Postgraduate) Student Mentioned "Access to Many Sources and References that Enrich and Enrich Learning Beyond the Limits of Accredited Books, So the Student Can See Beyond the Limits of the Subject and this will Indirectly Increase the Productivity of Learning."

Added A (Bachelor) Student "The Doctor Recommends Learning and Mobile and we Take Basic, For Each Project Material, Searching with Internet, Based on Previous Knowledge and Reference to Sources."

While with Regard to the Mobile Learning Management Service Factor such as Lecture Follow-Up and File

Planting, A (Postgraduate) Student "Communication Services, E-Mail, Material Registration, Payment of Fees Your Bills, Appointments and Postponement of Lectures, Discussion of Certain Topics, Exchange and Share Research among Students, Correspondence with Faculty Members, E-Library, and Search for Articles, Letters, and Suggestions, Is Used to Read PDF Files."

"They Can Be Encouraged by Giving them Tasks, Uploading Materials Online and Taking Online Exams," A (Bachelor) Student Said.

As for the Student Characteristics Factor, A (Postgraduate) Student Mentioned "The Culture of Students, Previous Knowledge, Student Differences."

"Depends on the Student, I Have the Ability to Study Alone, but Lectures are more Possible," Added A (Bachelor) Student.

Previous Student Responses Indicate that the Educational Material and Content Designed for Mobile Learning are an Influential Factor in the Use of Mobile Learning in Instructional; Mobile such as Lecture Follow-Up, File Dispatch and Processes Facilitate Mobile Learning;

It is Followed by the Lowest 24\% For Scientific Research And Flexibility; as for Flexibility, A (Postgraduate) Student Noted that "System Flexibility is an Important Tool for Learning to Use Device." 
Scientific Research and Flexibility have been the Lowest as One of the Factors Influencing the Use of Mobile Learning in Instructional.

The Researcher Believes that If the Student does not Take Advantage of the Innovative Moment, It Can Go and not Return, Therefore Mobile Learning Can Be One of the Best Solutions to Exploit These Moments, Therefore the Factors Referred to Require Jordanian Universities to Take Care of the Faculty Members and If Necessary to Train them to Use Mobile Learning, Where A Reciprocal Relationship between them and Students Is Built to Make this Type of Learning A Success.

In the Same Context, Faculty Members Should Take Care of Scientific Content and Instructional Design in A Way that Increases the Communication Skills Between Students and Opens Up Great Prospects for the Exchange of Ideas Rather than Monopolizing.

The Efficiency of Students is also A Factor in the Use of Mobile Learning;

The Flexibility and Speed of Mobile Learning Stimulates this Learner to Desire and Raise Awareness of Mobile Learning.

But in the Reality of Jordanian Universities Students Need Training Before Starting Mobile Learning, and this is What A (Bachelor) Student Pointed "Platform Training, Instructions to Enter the Platform, The Platform Atmosphere Detailed the Most Useful Platforms for Students."

Some Faculty Members also Associate Student Participation in Groups with Real Student Scores, with A (Postgraduate) Student Noting that "The Percentage of Faculty Members Who Share our Groups is about A Quarter of the Members. Some Faculty Members also Suggest that there are Signs of who Participates in the Groups and Enriches the Discussion."

It is Clear From The Responses of Faculty Members and Previous Students about the Answer to the Factors Influencing the Use of Mobile Learning in Instructional,

There Are Common Factors Among Them:

1. Faculty Members in Terms of their Adoption of Mobile Learning, their Role in the Design of the Electronic Material, and their Role in Encouraging Students.

2. Provide an Environment that allows Communication, Participation, Opinion and Feedback.

3. Students in Terms of their Characteristics, Needs, Culture, Awareness of Mobile Learning and Training.

4. The Need for A Clear and Special Learning System that Supports Mobile Learning.

5. The Way Material and Content are Designed and the Standards of Digital Content Dissemination are Adopted.

6. Educational Services, Applications and Programs that Support Mobile Learning.

7. Specifications of Mobile Learning Devices.

\section{Discussion of Results}

Discussion of the Findings Related to Answer the Main Question States: "What are the Factors Influencing the Use of Mobile Learning in Instructional in Jordanian Universities from the Point of View of Experts (Faculty) and Students?

The Main Question was Aimed at the Factors Influencing the Use of Mobile Learning in Instructional in Jordanian Universities from the Point of View of Experts (Faculty) and Students, Where it Contained (35) Factors Facing Jordanian Universities in the Use of Mobile Learning in Instructional and the Results were Found to be Consistent Studies of Lai and Mao (2014); Nawi, Hamzah, Ren and Tamuri (2015); Ogunlade, Olafare and Sakaba (2016); Karimi (2016); Hamidi and Ghavoshi (2017); Almaiah and Alismaiel (2019).

Both Faculty and Students Agreed on the Following Factors: First: Faculty Members in Terms of their Adoption of Mobile Learning, Their Role in the Design of the Electronic Material and their Role in Encouraging Students.

The Researcher Attributes the Result to Fact that the Faculty May Reject Change and Consider Mobile Learning A Waste of Teacher and Student Time, Trying to Demonstrate the Importance of Mobile Learning is Important to the Faculty.

The Result is that Training Shortens the Effort and Time of how Mobile Learning can be Used in Instructional, Universities May have Faculty Members Who Do not Have the Skills to Use Mobile Learning Applications, Which May Weaken their Use in Instructional, So Universities Have Taken the Decision to Train before Actually Using Mobile Learning.

Second: to Provide an Environment that Opens the Way for Communication, Participation, Opinion and Feedback. The Wheatley Model of Building Learning Emphasizes Collaborative Groups that Help Improve the Skills of Collaboration and Communication between Students, Which Helps to Discover the Problem Where One Group Includes One or More Students, To Plan and Implement the Solution of the Problem and to Participate in the Discussion of Tasks so that Each Group Presents its Solution to the Problem and the Methods Used to Deepen Their Understanding of All Solutions and Modify and Revise their Thinking (Mohammed, 2004).

The Researcher Attributes the Result to Ability of the Teacher and Students to Communicate and Exchange Ideas in Activities and Tasks Where Mobile Learning is based on Applications and Tasks that Require 
Interaction and Participation, and this is due to The Awareness of the Teacher and Students.

Third: Students in Terms of their Characteristics, Needs, Culture, Awareness of Mobile Learning and Training.

Students' Characteristics of Personal Creativity, The Expected Performance of Students and the Learning Style are Factors Influencing the Use of Mobile Learning (Karimi, 2016).

The Result is due to Material Matters in the Student's Desire When He or She to Enter the University Only to Obtain A Certificate;

Fourth: The Need for A Clear and Special Learning System that Supports Mobile Learning. The Criteria for Designing and Delivering Educational Content are Taken into Account When Designing Mobile Learning and the Techniques for Designing the user Interface through Mobile Devices and the Success of Mobile Learning Depends on the Capabilities of the Mobile Device and Technological Software. The Network's Connectivity Capabilities as well as Digital Content Include its Components, Components and Way of Dealing with it (Chernoubi, 2011).

The Result is that Teaching Process is Organized and Linked to it is not Random, it Needs A System from Student Identification to Evaluation, A System that Takes Into Account How to Deal with Digital Content, Perform Tasks and Activities, How to Conduct Electronic Tests and How to Proceed With Learning Singles and Collective.

Fifth: The Way Material and Content are Designed and the Standards for Publishing Digital Content are Adopted. The Quality of Electronic Materials is Seen by Assessing the Quality (Text, Graphics, Multimedia), Text Clarity, the Organization of Hyperlinks and the Use of Appropriate Methods and Techniques (Kazaine, 2015).

The Criteria Include the Preparation of Audio and Video Sources, The Use of Colors, The Presentation of Maps, The Use of Animations, The Presentation of Video Clips and the Recruitment of Sound Effects (Hamza And Ajami, 2013).

The Researcher Attributes the Result to the Fact that Mobile Learning Includes Digital Content Displayed through the Applications of Mobile Devices, If the Content is not Academically and Technically Designed in its Ease of Presentation and Circulation it Will Weaken the Learning Process, it is not Only Important to Use Applications that Have Provided Many Services, but also the Content is One of the Key Elements of Curriculum that May be Judged the Development of the Institution of Education.

Sixth: Educational Services, Applications and Programs that Support Mobile Learning. There are Many Services Provided by Mobile Learning Devices, Including: Short Messages Service (SMS); Social Apps; Bluetooth; and Mobile-Memo, Which is A Tool in Collecting Information, Gaining Knowledge and Publishing Content-Related Questions During Learning Activities (Mehdi, 2017).

The Services Include the Presence of A Camera that Serves Many Educational Practices, Enables Students to Read Materials Electronically and Watch Lectures Using A Mobile Phone, Can Record in Multimedia Content and Allows the Camera to Document Visual Materials and Collect Scientific Data (Hilao and Wichadee, 2017).

The Researcher Attributes The Result to the Fact that the Use of Mobile Learning in Different Devices in Instructional Needs Applications as Indicated in Theoretical Literature of Applications Used in the Instructional Process, Instructional Through Mobile Learning Devices Requires Programs and Applications that Allow to Take into Account Individual Differences, Accomplish Projects and Activities, Allowing Communication, Helping the Development of the Student, Offering Enrichment Activities and Allowing for Evaluation.

Seventh: Specifications of Mobile Learning Devices. The Use of Mobile Devices in the Learning Process Indicates that the Process is Equipped with Various Communication Techniques, Allowing Information to be Exchanged Between Students and Teachers, The Delivery of Information in and Out of Classrooms (Issa, 2012).

The Result is that the Applications and Programs of Mobile Learning for Instructional Require Specifications for Devices Used Communication Networks, Recording Videos, Allowing Downloading of Mobile Learning Systems and Other Specifications that Allow the Instructional Process to be Conducted Through Mobile Devices in the Image Occasion.

\section{Recommendations}

Taking into Account the Factors Influencing the Use of Mobile Learning in Instructional in Jordanian Universities and Studying them Well, to Take into Account them When Using Mobile Learning in Universities.

\section{References}

Akman, O. and Kocoglu, E. (2017). Examining Technology Perception of Social

Studies Teachers with Rogers' Diffusion Model. International Education Studies, 10 (1), 39- 46.

Ali, L. (2018). The Influence of Information Technology on Student's Behavioural Room. Asian Journal of Education and Training, 4 (2), 102- 107.

Al-Armiti, M. (2015). The Impact of the Use of Mobile Learning and 
Interactive Board on the Achievement of Seventh Graders in Mathematics in Jordan. Unpublished Master's Thesis, University of Jordan, Amman, Jordan.

Bas, M. and Sarigoz, O. (2018). Determining the Readiness Levels of Pre-Service Teachers Towards Mobile Learning in Classroom Managment. Educational Research and Reviews, 13 (10), 382- 390.

Bukharaev, N. and Altaher, A. (2017). Mobile Learning Education has Become more Accessible. American Journal of Computer Science and Information Technology, 5 (2), 1 - 5.

Al- Chernoubi, H. (2011). The Effectiveness of the Diversity of Digital Content Delivery Media for A Unit In Mobile E-Learning Technology, The Type of Profession in Attainment and the Ability to Teach Continuous Education among Education Technology Professionals and their Attitudes Towards Mobile Learning. Education Al-Azhar University, Egypt,1 (146), 501-624.

Dai, G. Liu, Y. and Cui, S. (2018). Astudy on the Mobile Learning of English and American Literature Based on Wechat Public Account. English Language Teaching, 11 (6), 47- 66.

El- hussein, M. and Cronje, J. (2010). Defining Mobile Learning in Higher Education Landscape. Educational Technology and Society, 13 (3), 12- 21.

Fakomogbon, M. and Bolaji, H. (2017). Effect of Collaborative Learning Style on Performance of Students in a Ubiquitous Collaborative Mobile Learning Environment. Contemporary Educational Technology, 8 (3), 268- 279.

Gezgin, D. Adnan, M. and Guvendir, M. (2018). Mobile Learning According to Students of Computer Engineering and Computer Education a Comparison of Attitudes. Turkish Online Journal of Distance Education, 19 (1), 4- 17.

Hamidi, H. and Chavoshi, A. (2017). Analysis of the Essential Factors for the Adoption of Mobile Learning in Higher Education a Case Study of Students of the University of Technology. Telematics and Informatics, 35 (4), 1053- 1070.

Hamza, I. and Ajami, N. (2013). Educational and Technical Standards for the Employment of Mobile Learning in E-Training Programs in Kuwait. Arab Studies in Education and Psychology,4 (43), 1-51.

Hilao, M. and Wichadee, S. (2017). Gender Differences in Mobile Phone Usage for Language Learning Attitude and Performance. Turkish Online Journal of Distance Education, 18 (2), 68- 79.

Hsu, Y. and Ching, Y. (2015). A Review of Models and Frameworks for Designing Mobile Learning Experiences and Environments. Canadlan Journal of Learning and Technology, 41 (3), 1- 22.

Issa, K. (2012). The Degree of Readiness of Students at the University of Jordan to Keep Pace with the Future Challenges of Implementing Mobile Learning in the Field of Education. Unpublished Master's Thesis, University of Jordan, Amman, Jordan.

Karimi, S. (2016). Do Learners Characteristics Matter? an Exploration of Mobile-Learning Adoption in SelfDirected Learning. Computer in Human Behavior, 63 (4), 769- 776.

Kazaine, I.(2015). Quality Assessment of Electronic Learning Materials. Research for Rural Development, 1, 264- 270 .

Khalil, O. (2011). Instructional is a Profession. Journal of the Faculty of Education Bisyut - Egypt, 27 (2), 1-4.

Kielmann, K. Cataldo, F. and Seeley, J. (2012). Introduction to Qualitative Research Methodology Atrainig Manual. United Kingdom: Department for International Development.

Lacey, A. and Luff, D. (2009). Qualitative Data Analysis. Nottingham: The Nihr Research Design Service for the East Midlands.

Lai, D. and Mao, C. (2014). Astudy on Factors Affecting the Mobile Learning of Undergraduate Students in China. Scientific Research an Academic Publisher, 5(5), 372- 375.

Almaiah, M. and Alismaiel, O. (2019). Examination of Factors Influencing the Use of Mobile Learning System An Empirical Study. Education and Information Technologies, 24 (1), 885- 909.

Mehdi, Y. (2017). Mobile Phone Software in Science Based on the Comprehensive Design of the Development of Cognitive Abilities, Self-Assessments and Educational Achievement in Students of Multi-Level Classes in Saudi Arabia. Journal of Scientific Education - Egypt, 20 (1), 51-110.

Mohamad, I. and Al- ameen, A. (2014). Designing an Effective Mobile Learning Model by Integrating Student Culture. International Journal of Computer Science and Security, 8 (3), $75-83$.

Mohammed, M. (2004). The Regulatory Portal and Some Instructional Models Based on Building Thought. 4th Arab Conference, The Organized Entrance in Teaching and Learning - Egypt, Ain Shams University, Cairo, 112-96.

Nawi, A. Hamzah, M. Ren, C. and Tamuri, A. (2015). Adoption of Mobile Technology for Teaching Preparation in Improving Teaching Quality of Teachers. International Journal of Instruction, 8 (2), 113124.

Ogunlade, O. Olafare, F. and Sakaba, D. (2016). Individual and Technological Affecting Undergraduates Use of Mobile Technology in University of Ilorin Nigeria. Digital Education Review, 29, 124- 133. 
Parajuli, K. (2016). Mobile Learning Practice in Higher Education in Nepal. International Council for Open and Distance Education, 8 (1), $41-54$.

Patton, M. (2002). Qualitative Research and Evaluation Methods. London: Sage Publications.

Prasertsilp, P. (2013). Mobile Learning Designing a Socio Technical Modle to Empower Learning in Higher Education . Ajournal of Transdisciplinary Writing and Research from Claremont Graduate University, 2 (1), $1-12$.

Al-Qaraaa, A. (2013). The Design of Instructional is an Applied Vision. Amman: Dar Al-Shorouk.

Ramzi, H. (2016). The Effectiveness of the Mobile Learning-Based Electronic Content Management System in Developing Some of the Skills of Using Technological Innovations in Middle School Teachers. Arab Research Journal in the Fields of Qualitative Education,1 (1), 45-104.

Al-Subai'i, M. and Al-Ghamdi, N. (2014). Following A Proposed Training Program Based on Mobile Learning Through Smartphone Smart in the Development of the Instrction Performance of the School Student Specializing in Science and Mathematics at the Faculty of Education at King Abdulaziz University. Studies in Curriculum and Instruction Methods, 1 (202), 66-119.

Taylor, R. (2014). The Essentials of Nursing and Healthcare Research. Londona: Sage Publications.

Wali, E. (2008). Reinterpreting Mobile Learning an Activity Theoretic Analysis of the Use of Portable Devices in Higher Education. Unpublished Doctoral Dissertation, University of London, London.

Wang, M. Callaghan, V. Singer, E. and Sun, H. (2016). Design Engaging Mobile Learning for the Global Audience. The Eurasia Proceedings of Educational and Social Sciences, 4 (1), 1- 7.

Youssef, N. (2014). The Effectiveness of A Program Based on the Use of Mobile Learning to Develop Some of the Concepts and Mathematical Skills of Students of the Faculty of Education on the Path of Learning Difficulties. Journal Of Mathematics Education - Egypt, 17 (8), 167 - 291. 